Fecha de recepción: diciembre 2017 Fecha de aceptación: marzo 2018 Versión final: julio 2019

\section{Imágenes arrebatadas, archivos inapropiables. Contratiempos de la vigilancia de la DIPBA sobre la instalación de una sala comunitaria por parte de la Unión de Mujeres de la Argentina \\ Julia Kratje *}

Resumen: El objetivo de este artículo es analizar un legajo de 1957 generado por la Dirección de Inteligencia de la Policía de la Provincia de Buenos Aires (DIPBA) sobre la Unión de Mujeres de la Argentina (UMA), que contiene fotografías tomadas por los agentes del espionaje, así como fotografías confiscadas e imágenes incorporadas a materiales de prensa. El documento informa acerca de las actividades desarrolladas por militantes de la UMA en barrios marginales del Gran Buenos Aires para la instalación de una sala de primeros auxilios. Desde enfoques interdisciplinarios de Estudios visuales, Teoría feminista y Análisis del discurso, se indagan las implicancias de la presunción de peligrosidad que impulsa la elaboración del archivo por parte de las fuerzas policiales.

Palabras clave: Archivo - visualidad - género - montaje - mirada - DIPBA - UMA.

[Resúmenes en inglés y portugués en la página 135]

(*) Doctora por la Universidad de Buenos Aires. Docente en la Universidad de Buenos Aires, en la Universidad Nacional de las Artes, en la maestría en Estudios de Género de la Universidad de Ciencias Empresariales y Sociales, y en la maestría en Poder y sociedad desde la problemática del género, de la Universidad Nacional de Rosario.

\title{
Presentación
}

Este artículo presenta avances de una investigación colectiva, actualmente en desarrollo ${ }^{1}$, acerca de las comunidades discursivas y los regímenes escópicos involucrados en los llamados "archivos de la represión". El objetivo específico es analizar uno de los documentos generados por la Dirección de Inteligencia de la Policía de la Provincia de Buenos Aires (DIPBA) sobre la Unión de Mujeres de la Argentina (UMA), que además de los memorandos contiene fotografías tomadas por los propios agentes del espionaje, así como imágenes confiscadas y otras incorporadas a materiales de prensa que también fueron secuestrados. 
La Unión de Mujeres de la Argentina se fundó el 17 de julio de 1947 en la Reunión Nacional de Mujeres en la Ciudad de Buenos Aires, promovida principalmente por la dirigencia del Partido Comunista Argentino (PCA) e integrada por militantes de distintas adscripciones políticas: además de comunistas ${ }^{2}$, participaron anarquistas, trotskistas, radicales, peronistas, que se manifestaban a favor del divorcio, de la patria potestad compartida, del aborto, por el derecho a la vivienda, por las leyes de protección a la maternidad para las trabajadoras, por la igualdad de salarios entre mujeres y varones al realizar el mismo trabajo, por el estatuto del servicio doméstico, en el marco de las luchas por la liberación nacional y social de la Argentina y de América Latina. Tal como afirma Adriana Valobra, en la etapa inicial de esta agrupación, "más allá de la estrategia del PCA y la actividad comunista en la UMA, debe entenderse que la pretendida dinámica de masas, por definición, obligó a desbordar los límites partidarios" (2005: 76).

En el contexto de la Guerra Fría, la detección y la persecución de actividades consideradas "subversivas" eran tareas prioritarias para la instrucción policial. Precisamente, el acervo documental relevado contiene un registro pormenorizado de la vigilancia ejercida sobre la UMA en 30 legajos catalogados en carpetas que corresponden a la "Mesa C", que reúne información sobre personas, organizaciones y actividades calificadas por la DIPBA como "comunistas", y a la "Mesa Referencia", que incluye tanto el material que no podía ser encasillado en alguna de las mesas, como el que presentaba líneas de cruce con otras carpetas. Estudiar la conflictiva articulación de los mundos discursivos que se han conservado en el archivo de la DIPBA (actualmente, resguardado por la Comisión Provincial por la Memoria), que a lo largo de cuatro décadas ha recogido los informes mecanografiados por agentes del Estado que tuvieron a cargo tareas represivas, pese a las dificultades que la investigación acarrea (que abarcan cuestiones epistémicas, metodológicas, así como también subjetivas), permite enfocar ciertas huellas de una trama social profundamente afectada por violencias políticas, dictaduras, reclamos, represiones, manifestaciones colectivas, proscripciones, mitificaciones, en la medida en que la memoria se comprende como una práctica de reconstrucción de las formas de representación del pasado en conexión con las demandas de justicia del presente.

El caso que aquí indago está conservado en el Legajo № 63 (Mesa C, Carpeta 3), elaborado en 1957 (período inmediatamente posterior a la creación oficial del archivo de la DIPBA en 1956), en cuanto a las actividades desarrolladas por militantes de la UMA en barrios marginales del Gran Buenos Aires para la instalación de una sala de primeros auxilios. Desde una perspectiva interdisciplinaria de Estudios visuales, Teoría feminista y Análisis del discurso, busco aproximar algunas respuestas plausibles a la pregunta por las implicancias de la presunción de peligrosidad de las mujeres que militaban en la UMA, que impulsa los trabajos de campo y la elaboración de informes por parte de las fuerzas policiales.

\section{M: descorrer el velo}

Ernesto Hipólito, delegado regional por la localidad de San Martín, según consta en la firma y en el sello del Memorándum Nº 658 que el 17 de julio de 1957 dirige al Jefe de la Central de la DIPBA en La Plata, indica que desde el mes anterior se divisaron "activida- 
des clandestinas y de penetración", por parte de "organizaciones colaterales del partido comunista", que contrarían la normativa de la llamada "Junta de la Democracia". Se puede inferir que, con este nombre, el agente se refiere a la Junta Consultiva Nacional, un organismo constituido durante la dictadura militar encabezada por Pedro Eugenio Aramburu (1955-1958), tras el derrocamiento del gobierno de Juan Domingo Perón a manos de la autodenominada "Revolución Libertadora", que al derogar la Constitución de 1949 dejó sin efecto los derechos y las garantías sociales, políticos y económicos.

La voluntad de esclarecimiento, que está en la base de la información vertida en el documento, se sostiene a partir de una serie de polaridades que organizan el discurso. En primer lugar, la oposición entre superficie y profundidad: el "proselitismo" de las mujeres, según enuncia el delegado, "se llevaba a cabo encubriendo el verdadero carácter que las inspiraba". Ante "versiones contradictorias", el informante despliega un relato a fines de aclarar los hechos. La historia narrada es la siguiente ${ }^{3}$ " "elementos comunistas estarían construyendo sala de primeros auxilios y salon [sic] de conferencias". En verdad, se trataría de una "acción de infiltración" en "barriadas pobres y de emergencia" que se encuentran bajo la jurisdicción de la comisaría de Munro, una localidad del partido de Vicente López, en la Provincia de Buenos Aires.

En segundo lugar, en relación con el "personal femenino cumpliendo tareas de infiltración", que llevaron a investigar sus acciones "a fondo", se delinea la polaridad entre religión y ateísmo: un letrero con la sigla de la entidad "U.M.A.", precariamente colgado de "un rancho de la familia compuesta por PEDRO LOPEZ y familiares", estaba inicialmente asociado al colegio Santa Teresita, perteneciente a la congregación San José, de la localidad bonaerense de Florida: "la Madre Superiora del Instituto", según revela el policía, "admitió que en efecto la presidenta de una organización que se titulaba UNIÓN DE MADRES ARGENTINAS, de carácter católico, había solicitado la colaboración de esa congregación para llevar a cabo una obra en conjunto que beneficiase a esa zona (...). La mencionada presidenta se trataba de ALMA N. L. DE FAIKENBERG”. Más allá del dato de color por el nombre de pila de la activista, el catolicismo de las monjas se perfila como antagónico de la "ideología izquierdista" ligada al "personal obrero" (el feminismo no es señalado como parte de dicha cosmovisión).

En tercer lugar, según se desprende a partir de las líneas preliminares, el informe devela la ambivalencia de la letra " $M$ " en la elaboración de la sigla de la agrupación, a partir del antagonismo entre "mujeres" y "madres": la Madre Superiora (junto a otras Hermanas) habrían sido engañadas por las Mujeres comunistas que ocultaron su militancia haciéndose pasar por madres de familia. Así, pues, se presume, de un lado, ingenuidad e inocencia por parte de las monjas, y, del otro, "cortina de humo" (para los organismos de seguridad e inteligencia) y "embaucamiento" (para el vecindario) por parte de las militantes: "se uso a las religiosas para hacerlas interceder ante las autoridades Municipales, para lograr el permiso respectivo de habilitación de locales que se construirían de la manera siguiente: UN SALON PARA ENSEÑANZA DE CORTE Y CONFECCION, ademas ayuda a los escolares para su preparacion y estudio, que llevarian a cabo las hermanas religiosas; y una sala de primeros auxilios, cuyo sostenimiento y asistencia estaria a cargo de U.M.A.”.

En cuarto lugar, estrechamente relacionado con la cadena binaria que organiza el discurso de la vigilancia, las actividades que estarían a cargo de las devotas (metafóricamente 
llamadas "madres", pese a que su cuerpo se presenta como desexuado y, naturalmente, no fecundado) y aquellas que cumplirían las militantes responden a tipificaciones recurrentes para el imaginario tradicional: por una parte, corte y confección para la educación de las niñas; por la otra, prevención y atención de la salud para los vecinos que padecen situaciones de pobreza y vulnerabilidad. Se conjetura que el engaño ha tomado tal magnitud, que "todas las familias han pedido la bendición de las instalaciones": del claustro religioso al barrio aledaño, la "infiltración" deja entrever atisbos de la formación de "una corriente de opinión", que el delegado Hipólito se permite diagnosticar como la secuela de una irresponsabilidad oficial respecto de las medidas antisubversivas: "La labor comunista se ve una vez mas auxiliada por la falta de propaganda, por parte del Estado, tendiente a demostrar y hacer conocer al pueblo, cuales son las entidades colaterales del comunismo". De las monjas al pueblo, el alcance de las acciones veladas parecería demostrar una cualidad persuasiva altamente eficaz.

En 1931, el cineasta austríaco Fritz Lang estrena $M$ (que en la Argentina se distribuyó bajo el título El vampiro negro), primera película sonora, considerada como precursora del film noir. En lo que a este trabajo respecta, el drama en torno a los crímenes en serie cometidos por un psicópata aterrador sirve, apenas, para evocar la trama policial elaborada a partir de la identificación clara de las figuras de la víctima y del victimario, de inocentes y de villanos, de personas engañadas contra quienes se convierten en una amenaza presuntamente letal para la sociedad. El desconcierto generado por el hecho de que la "infiltración" haya estado protagonizada por mujeres se debe, para el espía, a su condición de madres en potencia (según la ecuación más extendida: mujeres = madres, que sobre todo se ha venido desmontando desde la segunda ola del feminismo), aunque la historia hubiese revelado que, por cierto, se trataba de militantes. Estamos, entonces, ante un caso cuyo montaje argumentativo parece recurrir al marcador sintagmático del fundido encadenado, una técnica usual del expresionismo alemán, por el cual las figuras se van disolviendo al tiempo que se funden y sobreimprimen unas a otras, mientras el paulatino des-cubrimiento afianza la imagen del plano siguiente: la $\mathrm{M}$ de "madres" era, en realidad, una $\mathrm{M}$ de "mujeres" que, en el fondo, encarnan el riesgo mayor desde la óptica de los organismos represores: la militancia comunista.

\section{¿Esto ha sido?}

"Una foto es siempre invisible: no es a ella a quien vemos". Roland Barthes, La cámara lúcida (2006: 32)

En la serie de fotografías que el delegado policial adjunta a su informe "para una mayor ilustración", hay algunos materiales que despiertan la atención, puesto que son a todas luces inesperados en función del ethos objetividad que caracteriza al discurso de la DIPBA 4 . Como he analizado en otra ocasión, a mediados del siglo veinte las imágenes incorporadas a los legajos sobre la UMA eran vistas como piezas complementarias del discurso verbal. Al respecto, me interesa señalar que el lugar "complementario" da cuenta de una diversificación de los regímenes escópicos, que anticipa el momento de transición de un paradigma 
logocéntrico hacia uno más centrado en la imagen ${ }^{5}$. Pese a que no sepamos cuál ha sido el destino de las imágenes ( han sido destruidas), sí podría suponerse que las poquísimas fotografías archivadas en los legajos no se conciben apenas como "secundarias" respecto del discurso verbal -aunque se las defina a modo de "ilustraciones"-, sino que tienen un rol importante para la configuración de la historia a cargo de los agentes policiales; una historia violenta hecha de abusos, de engaños y de infiltraciones, que Ernesto Hipólito se va ocupando de contar. En este punto, es preciso recordar que todo archivo supone operaciones de construcción, que recortan y organizan los acontecimientos: por esta razón, no es posible el acercamiento pleno a la "realidad" de lo que ha sucedido. Para el caso de la comunidad de la DIPBA, la inspección, el registro y el ocultamiento, siguiendo a María Ledesma, permanecen "como fragmentos insignes de una totalidad perdida" (2018b: s/n). Por ello, nuestra indagación sólo puede tomar como objeto las huellas y los vestigios que han dejado marcas verbales y visuales en un esforzado entramado de conjeturas, de observaciones que se quieren imparciales, de indicaciones a título personal e, incluso, de supuestas "pruebas" esculpidas en imágenes. El informe incluye nueve fotografías (las primeras ocho fueron tomadas por los servicios de inteligencia ${ }^{6}$, mientras que la novena ha sido confiscada): una foto del "rancho" donde funcionaba la sala de primeros auxilios; una imagen de otro "rancho" en el que se hacían reuniones; una "vista del rancho cuya inauguracion no se ha efectuado"; "otra vista de la futura sala de primeros auxilios"; tres fotografías que muestran instalaciones de las religiosas y de la UMA; una "vista parcial" del barrio; y una foto carnet que pertenecía "a quien se titula Presidenta de la Organización Comunista".

Como escribe Gisèle Freund, la técnica específica de la fotografía, "la reproducción exacta de los hombres y de las cosas, tal y como se presentan a nuestros ojos, le confiere un aura de verdad" (2008). En este aspecto reside, justamente, para Roland Barthes, el enigma que la hace fascinante. Su estudio, siguiendo al autor de La cámara lúcida, es también una reflexión sobre la Muerte: la evidencia del Esto ha sido, que aparece como una obstinación del referente en estar siempre ahí. La tesis de Barthes es conocida: lo que la Fotografía reproduce al infinito únicamente ha tenido lugar una sola vez; o sea, la Fotografía repite mecánicamente lo que nunca más podrá repetirse existencialmente. Es por eso que no puede salirse del puro lenguaje deíctico.

Para la DIPBA, el material fotográfico -cuyos criterios de inclusión no aparecen explicitados, así como tampoco se menciona quiénes son los fotógrafos que acechan a los sujetos, obviamente sin su consentimiento, y que capturan a escondidas las situaciones desde ángulos cercanos o distantes- constituye la demostración objetiva de la verdad de los hechos observados y trasladados a los informes. Su valor de constatación jamás es puesto en duda. Sin embargo, lo curioso es que, más que revelar estrictamente su adherencia al referente, varias imágenes abren un abanico de inferencias y de posibilidades que apuntan tanto en dirección al pasado que se procura registrar, como al futuro que se figura como una consecuencia susceptible de ser anticipada por el ojo de la vigilancia. Veamos en qué consiste esta operación de registro en imágenes de signos que no plasman eventos que hayan sido contemporáneos a su captura, sino que de alguna manera estarían pasando por alto la autentificación (según Barthes, esencia de la Fotografía, que reside en ratificar lo que ella misma representa). 
Los acontecimientos que no suceden en el universo fenoménico observable por la investigación humana se denominan "contrafácticos". En este sentido, algunas de las fotografías estarían retratando los espacios que en el pasado permitieron, o en el futuro habilitarían, corroborar las hipótesis del espionaje. Dicho de otra manera, las circunstancias a las que el espía se refiere en el informe no coinciden con aquellas que fueron capturadas por el objetivo de la cámara, sino que las imágenes se resignifican por medio de intervenciones escritas. Para dar cuenta de su existencia, en las piezas I, III y IV se añaden marcas gráficas ("A"): "A) Indica donde se hallaba instalado un cartel que decia 'SALA DE PRIMEROS SUXILIOS - U.M.A.' (...) A) Indica lugar donde se colocara ${ }^{7}$ el cartel indicando la entidad organizadora (...) A) Igual indicacion que la anterior". A su vez, las imágenes tienen el poder de dar cuerpo a las especulaciones.

Estamos, por lo tanto, ante una afectación mutua de los discursos verbales y visuales. Y la manera en que ambas dimensiones se combinan podría pensarse a partir de la idea constructivista del montaje ${ }^{8}$ : aunque el archivo jamás cuestione la supuesta "objetividad", en dichas fotografías son las intervenciones gráficas las que hacen aparecer, como una revelación profana, esa "verdad", precisamente porque se trata de espacios deshabitados (no hay personas retratadas). El valor probatorio de la fotografía con respecto a la realidad es consecuencia de esta forma precaria, pero eficaz, de montaje. Por más que se borren las sospechas acerca de la certeza de los eventos informados, las imágenes no son medios transparentes y, por eso mismo, necesitan de la intervención del policía para conducir la mirada en el proceso de reconstrucción de la historia. Esto se explica porque el vínculo entre las fotografías y aquello a lo que refieren está escindido desde el comienzo: es producto de operaciones técnicas e ideológicas de captura en función de una interpretación encarnada, aunque desde el discurso de la DIPBA se pretendan borrar las marcas subjetivas.

La incorporación de fotografías de emplazamientos que atestiguaron o que anticiparían su funcionamiento como locaciones para el desarrollo de "tareas de neto corte comunista", pero que en la actualidad en la que fueron tomadas no lo habían sido o no lo serían aún, guarda coherencia con una apreciación que se incluye hacia el final del memorándum. El delegado sostiene que "lo evidenciado" gana fuerza por "la participacion en los hechos de la supuesta HILDA LOPEZ DE BARROS, de quien no se han podido obtener otros datos de filiacion, a pesar de todo el trabajo realizado. Se considera que ella ha sido el agente de captacion y que ha puesto en contacto a las hermanas religiosas con la celula de U.M.A. a cuyo efecto a fingido fe catolica”. De la ilustración más fehaciente al rumor menos demostrado, las imágenes se retroalimentan con las reflexiones aceleradas por el afán represivo de las fuerzas de espionaje. ¿Estamos, por ventura, frente a un trazo minúsculo de ficcionalización que asomaría, como un exceso indomable, a través de la mirada fríamente documental? Este podría ser un interrogante abierto por la yuxtaposición de imágenes en un archivo que desconoce con deliberación el estatuto de cada una de ellas (originales, secuestradas, robadas). Con todo, quizá tan sólo se trate de un ejercicio de presiones que, en sus vueltas paradojales, bosquejan el mundo imaginario del entorno policial, protagonizado por el fotógrafo, obediente, que cumple la debida obligación de ir a los lugares oportunos para encontrar evidencias que den crédito no sólo a la palabra del informante, sino por medio de ella a los dictámenes de la Dirección de Inteligencia en el contexto de las órdenes impartidas por la "Junta de la Democracia". 
En esta línea, un memorándum del 23 de julio del mismo año, cuyo objetivo es "Producir información", se explaya en la justificación de las pistas que el informante Hipólito había detectado (y que, pese a que no lleve ninguna firma, podemos conjeturar -sobre todo, a partir del uso no aleatorio ni escaso de las tildes- que ha sido redactado por otra persona): "Ante versiones circulantes en tal sentido, se dispuso practicar una exhaustiva investigación, la que permitió establecer que en el lugar mencionado funcionaba una entidad, que no era otra que la U.M.A. (Unión Mujeres Argentinas) y en el que había un letrero que indicaba la existencia de una sala de primeros auxilios, de carácter precario, en la que habitaba una persona llamada PEDRO LOPEZ, quien lo hacía en unión de sus familiares. (...) La presidenta de esa supuesta organización, no era otra que la señora ALMA NIDIA LOPEZ de FALKENBERG (...). Como podrá observarse, los hechos demostraban que la U.M.A., actuaba en nombre de una organización de madres católicas y no como tal, con el deliberado propósito de inducir a engaño y desarrollar su política ideológica de captación a que nos tienen acostumbrados".

"No era otra que", "a que nos tienen acostumbrados": las acciones que las mujeres desplegaron "para disimular las verdaderas actividades" eran tácticas para engañar a las monjas y al pueblo, "a la espera del momento oportuno para llevar a cabo su preconcebido plan de captación ideológica". Es decir: las mujeres militantes -que han venido demostrando su capacidad para disfrazarse de madres sencillas e inocentes- no pueden sortear tan fácilmente la mirada de la Dirección de Inteligencia, que por ello sale a la busca de fotos; algunas de estas, basadas en hipótesis contrafácticas que exponen los esfuerzos por anclarlas a su función denotativa.

\section{Fenómenos del montaje}

“(...) felicito a los vecinos por la obra llevada a cabo, exhortandolos a continuar por el triunfo de la empresa y el exito de U.M.A.- Agrego que había intercedido ante el Sr. Intendente de VICENTE LOPEZ, para obtener la colocacion de canillas (...).- Los exhorto a vivir en paz, y a bregar por la paz mundial, como asi tuvo expresiones son respecto a la necesidad de pacificacion interna del pais. (...) NINGUN GOBIERNO SE HABIA PREOCUPADO por el problema de la masa sufriente.- Ataco la pasividad de las autoridades con respecto al problema, que afecta al sector humilde pero laborioso". A estas alturas resulta incontestable que el fragmento citado, del Memorándum $\mathrm{N}^{\circ} 713$ del 24 de julio de 1957, confirma el retorno de la pluma de Ernesto Hipólito, especialmente atildada por la ausencia del entrecomillado para citar los discursos referidos, que pertenecerían a la vicepresidente de la UMA y a un médico que se pronunció de modo favorable a su causa. El delegado de la policía debió haber transcripto del registro oral grabado los discursos inaugurales de la sala de primeros auxilios.

Es interesante puntear que, en este documento, proliferan ciertos indicadores subjetivos e interpretaciones en primera persona: "Llama asimismo sobremanera la situacion"; "la Sra. de Falkember (...) gestiona una subvencion del Sr. Intendente para la Sala de Primeros Auxilios y que ya 'casi' la tiene conseguida"; "Me permito recordar". Esta vez, Hipólito usa comillas para destacar la inminencia del plan comunista ("casi”). Esta apreciación se 
refuerza gracias a las fotografías que "se obtuvieron" (por lo tanto, no podemos conocer quién ha sido la persona encargada de infiltrarse en el acto) durante la celebración "en forma encubierta, para no develar el caracter de la tarea". Son ocho fotos, de las cuales la última conlleva una nueva lectura ligeramente despegada de su condición factual: la de "el Dr. Cusnir, quien recibe de manos de vecinos un censo efectuado en la barriada (evidentemente util para la preparacion de celulas)", afirma el delegado sin dudarlo.

En los años veinte, el cineasta ruso Lev Kuleshov se encargó de mostrar a los espectadores una serie de secuencias fílmicas en las que se intercalaba, cada vez, la misma toma del actor Iván Mozzhujin con la imagen de un plato de sopa, de una niña en un ataúd y de una mujer recostada. Para la audiencia, la expresión de Mozzhujin -de hambre, de tristeza, de lascivia- cambiaba rotundamente de escena a escena. Este experimento sirvió para comprobar la influencia del montaje para la comprensión semántica de lo que vemos. En este sentido, se podría trasladar la teoría soviética para examinar la mirada que despliega Ernesto Hipólito, quien ve en la fotografía del Dr. Cusnir el germen de una conspiración.

\section{Lo evidente es invisible a los ojos}

"Hace diez años, en un crudo día de invierno, cientos de mujeres representando a más de cien organizaciones femeninas de todo el país, se reunieron en una memorable asamblea que dió nacimiento a la Unión de Mujeres de la Argentina”, cuenta Matilde Alemán en un artículo publicado en julio de 1957 en el número 75 de la revista Nuestras mujeres, que por aquel entonces era el principal medio gráfico de la agrupación", cuyo ejemplar "se hallaba en poder de la Sra. Falkemberg" y, luego de su apropiación, fue incorporado a las pruebas gráficas del informe policial.

La lectura transversal de estos materiales de prensa pone de relieve un contrapunto respecto del enfoque con el que la inteligencia retrata el antagonismo mujeres/madres sobre la base de la oposición entre camuflaje y autenticidad, tal como señalé más arriba. Desde la misma publicación, la maternidad no se presenta como una condición externa al discurso de la agrupación, sino todo lo contrario: los valores de la caridad y del decoro aparecen acentuados. Algunos ejemplos: "U.M.A. festeja asimismo los 70 gloriosos años de su presidenta Doña Margarita de Ponce, símbolo de lo más puro y abnegado de las madres de nuestra Patria", indica la bajada de un conjunto de fotografías que exhiben a las mujeres celebrando los diez años de la Unión de Mujeres de la Argentina. "Como madre católica hago un llamado a todas las madres de mi Patria para que unidas logremos que el precepto de Dios, aquel que dice 'Amaos los unos a los otros' sea cumplido, para que haya paz entre los hombres de buena voluntad. Invitamos a todas las madres, y en especial a las madres católicas, a firmar el llamamiento para el cese total de las experiencias atómicas", concluye una carta firmada por Celia Monti, publicada en el margen superior derecho de una página que, a su izquierda, tiene una columna, titulada "BIENVENIDO HIJO MIO!", sobre un método llamado "psico-profiláctico del dolor en el parto", destinado a educar a las "futuras madres". Más adelante, la revista contiene una sección acerca de "modas" y "cocina". En los dos tercios superiores de la página, sobre recetas para preparar "fideos con carne" y "tortilla de pan rallado al vino", la nota "TRANSFORMANDO un SACON" 
explica, paso a paso, cómo convertir "un sacón que usted ya no usa" en "un coqueto y abrigado saconcito para la hijita", y entonces, "sin mayor gasto, su niña estará a la última moda" (Nuestras Mujeres: s/n).

Así, pues, los informes de la vigilancia presentan como dicotómicas ciertas cuestiones que, en la práctica militante, estaban entramadas (mujeres/madres; tradición laica/catolicismo). La separación responde a una operación de lectura del espía, que viene predefinida por la mirada positivista y que encuentra en la militancia feminista (que desde las páginas de Nuestras Mujeres se define como "femenina") su gran fuera de campo: lo que en estos años ocupa la atención de los servicios de inteligencia es el comunismo y, en términos más generales, el amplio arco ideológico y político de la izquierda. Posiblemente, por este motivo, las acciones impulsadas por la UMA provocaron desconcierto, una actitud que en los documentos secretos se traduce en la voluntad de clasificar a los sujetos espiados de acuerdo con las rígidas categorías que provee el imaginario patriarcal combinado con la instrucción policíaca. La idea de que "la intensa acción ideológica" era desenvuelta por "el Partido Comunista por intermedio de sus colaterales" se basa en una visión verticalista y netamente conspirativa del activismo: así como las monjas fueron manipuladas, las mujeres se movilizan acatando la doctrina del PC. En este punto, Adriana Valobra sostiene: "Los servicios consideraban a las mujeres más susceptibles de ser engañadas por el comunismo internacional y sus 'pantallas' (como la UMA), las cuales mostraban avezada experiencia en movilizarlas. Esto también era alertado desde la prensa católica y los diarios comerciales. En este sentido, el anticomunismo que con tanto ahínco se perseguía en otras partes del globo no es el mismo que se perseguía en Argentina en el contexto de la Guerra Fría. (...) el de Argentina resulta imbricado con el antiperonismo, fundamentalmente en los años 60. En todo caso, y volviendo a las mujeres, la preocupación de este contexto era, precisamente, su capacidad de movilizar a otras en pos de ciertas demandas y objetivos" (2017: 38).

Sobre la revista incautada, quiero hacer una última observación. En una nota que ocupa una página completa, la composición de la grilla destaca tres fotografías que muestran abiertamente las tareas comunitarias emprendidas por la UMA. Las mujeres aparecen posando junto a vecinas y vecinos, niñas y niños, que habitan en un "barrio de emergencia" ubicado en el partido de Vicente López, donde se ha puesto en marcha una filial de la agrupación. El texto contiene fragmentos de una entrevista a "una mujer madura y su hija" respecto de la comisión que "dió vida a estas villas, quien le dio calor, energía, vigor": "UMA nos despertó, fue como una máquina”, se afirma. El testimonio (y la crónica en su conjunto) confirma con nombre y apellido la identidad de "las valientes mujeres" que impulsaron diversos reclamos (mediante petitorios por el agua potable, por la rebaja del pan, por la instalación de baños públicos, por la recolección de basura), que se suman a la sala de primeros auxilios que ya venía funcionando en el barrio. Sin dudas, las transformaciones de la infraestructura repercuten en una toma de conciencia: "Hasta ahora no hemos tenido más que barro, ahora vamos a cambiar las cosas, queremos vivir bien".

En 1950, Ingmar Bergman estrenó Till glädje, un título cuya translación al castellano es "Para la alegría". En esta obra del principal autor sueco del siglo veinte, la célebre oda $A n$ die Freude, incluida en la Novena Sinfonía de Ludwig van Beethoven, adquiere preponderancia para figurar los momentos de felicidad y los vaivenes anímicos de una joven pareja 
de violinistas que tocan en la misma orquesta. El film está entre las recomendaciones de la sección cultural de Nuestras Mujeres (a la par de "La ópera de dos centavos" de Bertolt Brecht), pero con una salvedad: "no pasa de ser una película común, como muestra habitual de lo que puede dar el cine sueco exhibiendo ambientes un tanto decadentes y conflictos entre neuróticos y mujeres pretendidamente libres", aunque "el realismo de lenguajes y de costumbres, resulta saludable ante la pacatería a que estamos acostumbrados". En esta dirección, es innegable que el universo sensible de la Unión de Mujeres de la Argentina contiene numerosas cuestiones en disputa, que revelan las tensiones entre determinados elementos dominantes (como el activismo barrial), residuales (como la religión y las relaciones desiguales de género en cuanto a las actividades reproductivas, productivas y militantes) y emergentes (como la oposición frente al atropello de las fuerzas represivas con respecto al plano social, y la crítica de los valores tradicionales ligados al arte), siguiendo a Raymond Williams (1980) en Marxismo y Literatura.

\section{Palabras finales: hacia una crítica iconoclasta}

Indagar el cruce entre comunidades discursivas y regímenes escópicos, a partir el análisis de los documentos generados por la Dirección de Inteligencia de la Policía de la Provincia de Buenos Aires sobre la Unión de Mujeres de la Argentina, permite ahondar en el estudio tanto los discursos verbales como de los visuales, o mejor dicho, de sus interacciones, con sus puntos de confluencia y de tensión: las fotografías no son consideradas como mero agregado ilustrativo de los informes, sino que constituyen una fuente primaria de la que los policías se sirven para realizar sus propias interpretaciones a partir de los sujetos y de las situaciones que espían, registran y observan en las imágenes. Si bien las fotografías que se conservan son muy escasas, se pueden clasificar según tres tipos fundamentales: 1. fotografías incautadas; 2 . fotografías tomadas por la DIPBA; 3 . fotografías de la prensa. La diversidad de sus orígenes es un indicador de la importancia que la imagen presenta inclusive desde tiempos tempranos de la DIPBA.

Para finalizar este breve estudio, interesa asimismo señalar tres líneas de apertura para las investigaciones sobre los archivos de la represión, que convergen en el presente trabajo. En primer lugar, el despliegue de los enfoques interdisciplinarios de Estudios visuales y Análisis del discurso, cuyo mutuo enriquecimiento se pone de relieve en el abordaje de casos particulares, como los materiales desclasificados sobre las actividades de espionaje de la UMA. En segundo lugar, otro aporte con relación a los legajos que integran dicho corpus es la perspectiva feminista, que ofrece la posibilidad de investigar los verosímiles sociales sobre los que se asienta la mirada policial, que aparece tensionada por la desigual distribución del poder entre mujeres y varones. En este sentido, la noción de género en el cruce con otras categorías socioculturales (clase, cosmovisión, procedencia geográfica, religiosidad) permite explorar la construcción discursiva (tanto verbal como visual) de los sujetos vigilados desde la atención puesta en las presunciones y en las valoraciones sexistas de los propios encargados de realizar la vigilancia. A la vez, el archivo preserva ejemplares de una publicación emblemática de la UMA, la revista Nuestras Mujeres, que habilita una reflexión sobre las vicisitudes del activismo feminista. Tantas veces eclipsado por la histo- 
riografía hegemónica que, por ejemplo, encumbra a dirigentes e intelectuales orgánicos de la Revolución de Octubre desde visiones androcéntricas, el estudio de los recorridos de las mujeres por el comunismo implica un reposicionamiento de la mirada para estimar -en su justa medida- la movilización sensible, social, ideológica y política que ellas han impulsado desde múltiples focos de acción, atravesados por los conflictos, las contradicciones y las heterogeneidades inherentes a todo fenómeno cultural (y que, por supuesto, recorren la experiencia de las izquierdas, y la agenda del PCA en particular, en cuanto al modelo heteronormativo que sellaba su defensa de las "madres trabajadoras").

Por último, en tercer lugar, vale insistir en la importancia de investigar, desde un marco teórico específicamente dirigido al estudio de la imagen, las fotografías incluidas en el caso de la UMA. Para ello, me he servido de algunas nociones vinculadas al montaje cinematográfico (como el fuera de campo, el fundido encadenado, el found footage, el efecto Kuleshov), siguiendo el enfoque vanguardista de la escuela soviética, a fines de realizar una lectura - política y poéticamente- a contrapelo de la mirada "objetiva" y "neutral" que los organismos represores se atribuyen, ignorando por su posición de poder el carácter de constructo de las imágenes: ya no se trata de presuponer que las fotografías calcan positivamente los sucesos, ni tampoco que el hecho de archivarlas contendría en sí mismo alojado el dato empírico. Si la concepción que la DIPBA tiene del vínculo entre realidad y representación se vanagloria en la transparencia y la creencia en la autenticidad de la documentación mecánica de la realidad, llevar la mirada a las limitaciones de las imágenes para registrar el mundo (puesto que es inevitable recortar lo que se muestra, por el encuadre de la cámara y por el cuerpo que la sostiene) es una manera de iluminar las opacidades e intervenir el archivo para desentrañar sus procedimientos enunciativos y visuales que, en cierto modo, se dirigen menos al sentido de la visión que al imaginario que la envuelve. Quedará para futuros trabajos evaluar los alcances críticos de estas aproximaciones en torno a las formas de representación de los acontecimientos traumáticos que marcaron a fuego la historia argentina.

\section{Notas}

1. PICT-2015-3712. Título: "La comunidad discursiva del Archivo de la Dirección de Inteligencia de la Policía de la Provincia de Buenos Aires (DIPBA)”. Directoras: María Alejandra Vitale y María del Valle Ledesma. Universidad de Buenos Aires.

2. Según María Eugenia Marengo, "si bien la intencionalidad de las integrantes de la UMA siempre fue apuntar a todas las mujeres sin distinción política partidaria, con el tiempo sobresalieron los intereses del Partido Comunista" (2012: 164).

3. En la transcripción de todas las citas del legajo, se conservan las palabras textuales, incluyendo los numerosos errores ortográficos y gramaticales. Vale esta aclaración para evitar la recurrencia de marcas de distanciamiento -como, por ejemplo, "[sic]"- que pueden resultar excesivas y obstaculizar la lectura del informe, ya de por sí enrevesado.

4. Sobre la construcción de la imagen de sí por parte de la DIPBA, remito al trabajo de Alejandra Vitale (2016). 
5. Esta afirmación se basa en la hipótesis propuesta por María Ledesma (2018a), a partir de nociones forjadas por Michel Foucault y por Martin Jay, retomada para el estudio de la vigilancia que la DIPBA ha ejercido sobre la UMA en un ensayo reciente (véase Kratje, 2018).

6. Se trata de fotografías tomadas desde una perspectiva subrepticia que, siguiendo a Ledesma, podemos definir como "mirada de soslayo": "un tipo de mirada horizontal que mantiene a quien mira por fuera del campo de visión del vigilado" (2018b: s/n).

7. Pese a que la falta de uso de tildes podría conducir, en este caso, a considerar la posibilidad de un pretérito imperfecto del subjuntivo, se trata del futuro del indicativo: "colocará", ya que refiere a la paradójica "vista de la futura sala": una sala del futuro que el vigilante da por vista.

8. Véase, al respecto, el recorrido que Emilio Bernini efectúa por las apropiaciones experimentales y documentales de la práctica del found footage.

9. Siguiendo a Valobra, Nuestras Mujeres "cuenta con un momento fundacional, un período formativo entre 1947 y 1949. Merced a esta estrategia política, el PCA intentó reconstruir estructuras alternativas a las partidarias: las organizaciones de masas. Estas pretendían conjurar la peronización y la manipulación estatal. (...) Si bien no podía dudarse de la hegemonía comunista en la UMA, lo cierto es que en las filas de la agrupación se enrolaron mujeres de otras filiaciones, laicas católicas y, fundamentalmente, mujeres sin filiación partidaria. La dinámica de los años formativos estuvo atravesada por las tensiones que la constitución del agenciamiento femenino supuso" (2017: 36). Tal como indica la investigadora, el incremento de la persecución a partir de 1949 y el primado de intereses partidarios marcan un segundo período, regulado por el cerramiento de la agrupación en las filas del partido: "Parece factible que, en las condiciones del contexto social de fines del primer gobierno peronista, las comunistas - grupo mayoritario impulsor de la UMA- hayan intentado capitalizar la inversión que hacían en el movimiento y tratado de limitar la injerencia de otras entidades que dispersaban el foco al establecer constantes discusiones que dilataban decisiones. Las persecuciones se pudieron visualizar como habilitantes para tomar decisiones sin consulta a esos grupos minoritarios o que no eran perseguidas como las comunistas de la UMA, precisamente, porque no eran comunistas. Los espacios de negociación entre diversas agrupaciones intervinientes en la UMA parecen haberse reducido o disgregado, aunque no necesariamente desaparecido" (2017: 37).

\section{Referencias bibliográficas:}

Alemán, M. (1957). “U.M.A. 1947- 13 de julio - 1957”, Nuestras mujeres, $\mathrm{N}^{\circ}$ 75, julio de 1957, Buenos Aires.

Barthes, R. (2006). La cámara lúcida. Notas sobre la fotografía. Buenos Aires: Paidós.

Freund, G. (2001). La fotografía como documento social. Barcelona: Gustavo Gili.

Kratje, J. (2018). "Shot, countershot, off-screen space: espionage and DIPBA's gaze on the Argentine Women Union", AYOR 8 - The "Deep State" as Rhetoric, pp. 72-80.

Ledesma, M. (2018a). "The gaze in the surveillance of political groups by the DIPBA. Some problems for researchers", AYOR 8 - The "Deep State" as Rhetoric, pp. 81-90. 
Ledesma, M. (2018b). "Dos masacres, dos miradas". [En prensa]

Marengo, M. E. (2012). "Lo aparente como real: Un análisis del sujeto 'comunista' en la creación y consolidación del servicio de inteligencia de la policía de la Provincia de Buenos Aires", Memoria Académica: http://www.memoria.fahce.unlp.edu.ar/tesis/te.875/ te.875.pdf

Valobra, A. (2005). "Partidos, tradiciones y estrategias de movilización social: de la Junta de la Victoria a la Unión de Mujeres de la Argentina”, Prohistoria, IX, 9, Rosario, pp. 67-82.

Valobra, A. (2017). "Las mujeres de los Partidos Comunistas de Argentina y Chile entre los '30 y '60”, Anuario de la Escuela de Historia Virtual, Año 8, No 11, pp. 23-46.

Vitale, M. A. (2016). "Vigiladores y espías. Imagen de sí, memoria y experticia en el Archivo de la DIPBA", Vigilar la sociedad. Estudios discursivos sobre inteligencia policial bonaerense, Ed. María Alejandra Vitale. Buenos Aires: Biblos.

Williams, R. (1980). Marxismo y literatura. Barcelona: Península.

\begin{abstract}
The objective of this article is to analyze a file of 1957 generated by the Directorate of Intelligence of the Police of the Province of Buenos Aires (DIPBA) on the Union of Women of Argentina (UMA), which contains photographs taken by agents of espionage , as well as confiscated photographs and images incorporated into press materials. The document informs about the activities developed by militants of the UMA in marginal neighborhoods of Greater Buenos Aires for the installation of a first aid room. From interdisciplinary approaches of Visual Studies, Feminist Theory and Discourse Analysis, the implications of the presumption of dangerousness that drives the elaboration of the archive by the police forces are investigated.
\end{abstract}

Keywords: Archive - visuality - gender - assembly - look - DIPBA - UMA.

Resumo: O objetivo deste artigo é analisar um arquivo de 1957 gerado pela Diretoria de Inteligência da Polícia da Província de Buenos Aires (DIPBA) sobre a União das Mulheres da Argentina (UMA), que contém fotografias tiradas por agentes de espionagem. , bem como fotografias e imagens confiscadas incorporadas em materiais de imprensa. O documento informa sobre as atividades desenvolvidas por militantes da UMA em bairros marginais da Grande Buenos Aires para a instalação de uma sala de primeiros socorros. A partir de abordagens interdisciplinares de Estudos Visuais, Teoria Feminista e Análise do Discurso, são investigadas as implicações da presunção de periculosidade que impulsiona a elaboração do arquivo pelas forças policiais.

Palavras chave: Arquivo - visualidade - gênero - montagem - olhar - DIPBA - UMA.

[Las traducciones de los abstracts fueron supervisadas por el autor de cada artículo] 